\title{
ERRATUM
}

\section{Progress on the small modular stellarator SCR-1: new diagnostics and heating scenarios - ERRATUM}

F. Coto-Vílchez, V. I. Vargas, R. Solano-Piedra, M. A. Rojas-Quesada, L. A. Araya-Solano, A. A. Ramírez, M. Hernández-Cisneros, J. E. Pérez-Hidalgo, A. Köhn-Seemann, F. Cerdas, F. Vílchez-Coto, D. Jiménez, L. Campos-Duarte, E. Meneses, M. González-Vega and S. Arias

doi:10.1017/S0022377820000677, Published by Cambridge University Press, 08 July 2020

The original version of this article was published with an editor's name misspelled in the acknowledgements. The correct acknowledgement should read as below.

Editor Per Helander thanks the referees for their advice in evaluating this article.

\section{REFERENCE}

Coto-Vílchez, F., Vargas, V., Solano-Piedra, R., Rojas-Quesada, M., Araya-Solano, L., Ramírez, A., Hernández-Cisneros, M., Pérez-Hidalgo, J. E., Köhn-Seemann, A., CERDAS, F. et al. 2020 Progress on the small modular stellarator SCR-1: new diagnostics and heating scenarios. J. Plasma Phys. 86 (4), 815860401. doi:10.1017/S0022377820000677 